\title{
Fuzzy-Expert System for Indicator and Quality Evaluation of Teaching and Learning Processes Online Study Programs
}

\author{
Yuniana Cahyaningrum ${ }^{1 *}$, Suryono Suryono ${ }^{2}$, and Budi Warsito ${ }^{3}$ \\ ${ }^{1}$ Master of Information System, Post Graduated School, Diponegoro University, Semarang, Indonesia \\ ${ }^{2}$ Department of Physics, Faculty of Science and Mathematics, Diponegoro University, Semarang, \\ Indonesia \\ ${ }^{3}$ Department of Statistics, Faculty of Science and Mathematics, Diponegoro University, Semarang, \\ Indonesia
}

\begin{abstract}
The quality of education is essential so that it needs to be improved. This study aims to design and realize an information system for monitoring and evaluating the quality of the online teaching and learning process using the fuzzy-expert system algorithm. By using the fuzzy-expert system model, the Tsukamoto method can monitor the online teaching and learning process. The tsukamoto method is used because it is very flexible. Fuzzy-expert system can process a lot of data and get better results than using the excel application. The assessment parameters in this study were the presence of lecturers and students, the suitability of the lecture material, the development of an academic atmosphere, the assessment of student skills, the suitability of learning support facilities and infrastructure, the performance of education personnel in the learning process, assessment of student attitudes, student knowledge, lecturers' role models, and lecturer performance in teaching. The fuzzy stages used in the system are the process of fuzzification, rules, and defuzzification. This study concludes that fuzzy assessment can be carried out by producing good evaluations for the value range of 80-100, enough for the range of values of 54-79, and less in the range of values $0-55$.
\end{abstract}

\section{Introduction}

The quality of education is essential, starting from the student admission process, the learning process while being a student, and the student's academic achievement. Improving and optimizing the education system for the wider community is the education system's responsibility [1]. In previous research, learning was carried out with a conventional system where students experienced points of saturation and boredom in existing learning; besides that, it also made the implementation feel slow because the process was not real-time and was less time-efficient [2]. To monitor the interaction between lecturers and students maximally so that achievements in the teaching and learning process can be fulfilled [3].

\footnotetext{
* Corresponding author: yun14n4@gmail.com
} 
Processing and presentation of monitoring lecturer performance still use a manual process, namely writing notes in a book. It is not uncommon for specific sub-sections to require these data; academic staff has problems collecting lecturers' data in recapping it into one part of the document to become a report, resulting in a delay in data presentation [4].

In further research, the development and use of the ISO 21001: 2018 standard is an educational organization management system adapted from ISO 9001: 2015. This standard is specially prepared for the education sector in achieving its goals and carrying out its primary function, namely providing quality education. One of the approaches taken in ISO is the PDCA (Plan Do Check Act) in the ISO 21001 framework [5]. Current education trends encourage the development of educational management that can connect with today's artificial intelligence technology [6] - Quality Assurance, or what is commonly referred to as quality assurance applied to tertiary institutions. Various attempts have been made to build an effective higher education with a quality assurance scheme. In its development, quality assurance schemes need to be examined from a global perspective. In the international world, people can clearly understand the problems in quality assurance schemes or are limited because of poorly designed programs or specific political and cultural backgrounds. Consequently, quality assurance schemes, one of the dominant schemes in higher education, begin by describing the context in which quality assurance schemes originate [7].

Fuzzy logic is the main constituent of the fuzzy expert system. Fuzzy logic uses the same patterns as how humans think. Therefore, fuzzy logic is used to handle information with inappropriate terms, such as height and age being young. The human brain can make decisions with uncertain, ambiguous data types, but computers can only manage with precise judgments. The computer can only understand data with a value of either a ' 0 ' or ' 1 '. Hence fuzzy logic is used to provide a kind of interface between the human brain and the computer. It can handle exact and obscure data at the same time. Fuzzy logic uses fuzzy sets that have values between 0 and 1 . The main components of a fuzzy expert system are Fuzzifier, Inference Engine, Fuzzy Knowledge base, Defuzzifier [8]. The Tsukamoto method is an extension of monotonous reasoning. The Tsukamoto method is also used to make essential decisions applied to a system with only one rule. Tsukamoto's method contains implications of any causal rules or input-output implications, consequently in the form of If-Then. The resulting output is a value for each fuzzy rule in the form of a crisp value based on the fire strength of the antecedent [9]. In an expert system, students' learning status, like their answers to treat, are recorded as their cognitive status, and their online learning behaviour is analyzed to determine its effect status. Inferential fuzzy is used to analyze students' cognitive and affective status by using fuzzy membership functions and inference rules. For example, the fuzzy membership function to analyze students' cognitive performance. In addition, the following fuzzy rules are used to determine the version of learning material given to each student based on their current learning status [10].

\section{Materials and Methods}

\subsection{Materials}

In this study, the fuzzy-expert system method with the Tsukamoto method is proposed to solve this problem. By using the fuzzy-expert system model, it can monitor the teaching and learning process. The use of fuzzy-expert systems has been widely used in several studies with relatively few error rates because the fuzzy-expert system can process many data with data that has a range so that it makes calculations easier to get results, fuzzy logic is also very flexible, meaning that it can adapt to data. Changes and uncertainties that 
accompany problems and being able to model very complex non-linear functions and build and apply experts' experiences directly without having to go through a training process [11]. One of the quality assurance systems that utilize technology is the Quality Assurance Evaluation System (QAES). This system policy has two models in its development, namely a model of action and a model of change; besides that, it has internal and external evaluation stages in its implementation [12].

\subsection{Methods}

This system is designed to reduce the level of difficulty in monitoring the teaching and learning process. It can facilitate information facilities to make it easier for lecturers to carry out teaching activities. This system is accessed online, which can facilitate curriculum staff in evaluating lecturer performance and monitor the teaching and learning process in the ISI Surakarta Batik Fashion Design study program. The ISI Surakarta Batik Fashion Design study program was established based on the Ministry of Education and Culture's Mandatory Decree Number 148 / E / O / 2012, which was previously named the D-IV Batik study program then underwent a name change to become the Batik Fashion Design study program. The use of fuzzy solves problems in monitoring the teaching and learning process, which is still conventional. This causes delays in reporting data in the ISI Surakarta Batik Fashion Design study program. Fuzzy-expert systems can process large amounts of data, making it easier to calculate and flexible.

The procedure section of this research describes the stages carried out in the study. The stages are carried out with the Systems Development Life Cycle (SDLC) with the agile method. The software development field has tried several methodologies to complete projects on time and take advantage of them. Software engineering provides the procedures and practices that must be followed during software development, and these are implemented in a variety of software. It acts as a pathway for the computer iterative.

Agile processes are iterative, meaning that changes can be made according to customer needs until the customer is satisfied. The agile methodology aims to achieve high productivity over heavyweight processes. It works on less planning and divides the task into small sub-tasks or small increments by teamwork effort. The team follows a software development life cycle phase with the following stages:

\section{Requirements collection}

Requirements collection is both an art and a science. This requires the analyst to work closely with the customer and utilize their communication and technical skills to bring up the underlying business needs that a system solution may address. One of the main obstacles is "jumping to the solution" with an inadequate understanding of operational problems and basic customer needs. Needs analysis is also fundamentally an exploratory and iterative process. Often, customers cannot state what they want until they see what they are asking for in a previous iteration of requirements with the IT team [13].

\section{Analysis}

System analysis is the decomposition of a complete system into its component activities to identify and evaluate problems, opportunities, obstacles, obstacles, which occur, and the expected needs so that improvements can be proposed.

\section{Designing}

Designing or system design is the preparation of implementation design which describes how a system is formed in drawing, planning and making sketches or arrangements of several separate elements into one complete and functional unit, involving the configuration of software and hardware components of a system.

\section{Coding}


Coding or coding is translating the results of the design process into a form of a computer program that is understood by computer machines.

5. Testing

Software testing is a critical element of SQA (Software Quality Assurance) and represents a comprehensive specification, design, and coding review. The test presented the abnormalities that occur in software development. During the initial definition and development phases, development seeks to build software from abstract concepts to possible implementations.

6. Maintenance

There are 3 reasons for the need for system maintenance, namely:

a. To correct errors or system weaknesses that were not detected during testing.

b. To keep the system up to date.

c. To increase system capabilities.

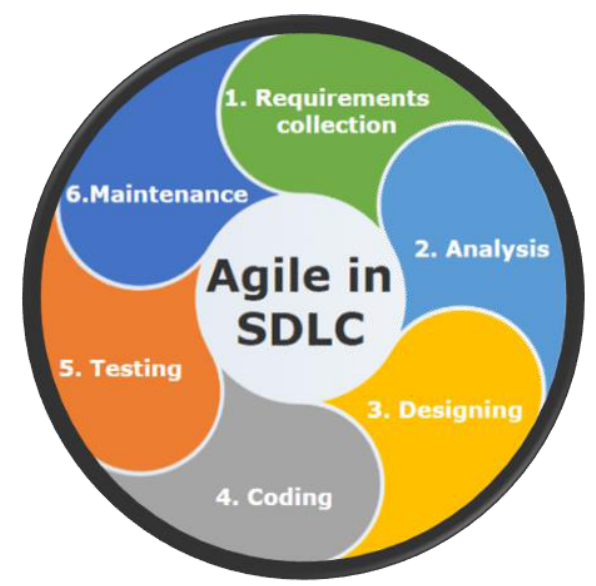

Fig. 1. Agile Stage.

This stage begins with determining what needs are needed for the system to solve problems or opportunities by identifying user needs to provide correct progressive solutions. In addition, at this stage, it also defines the output to be produced, the features of the application, and the functions of the application being developed [13]. At this stage, analysis is carried out by decomposing the complete system into its component activities by identifying and evaluating problems, opportunities, obstacles, which occur, and the expected needs so that improvements can be proposed.

At the system design stage, preparation for implementation design is carried out, which describes the system formed in drawing, planning, and making sketches or arrangements of several separate elements into one complete and functioning unit, involving the configuration of software components and system hardware. In the next stage, coding is carried out by translating the design process results into a form of a computer program that humans run with a computer machine.

At this stage, the program tests the critical elements of SQA (Software Quality Assurance) and presents a comprehensive review of specifications, design, and coding. The trial presented the abnormalities that occur in software development. During the initial definition and development phases, development seeks to build software from abstract concepts to possible implementations. At the maintenance stage, system maintenance is carried out to find any errors or weaknesses in the system that were not detected during testing to be more up to date. 
The model design that will be applied in this system is a fuzzy logic model with the Tsukamoto method. The flow chart illustrates the system workflow process that will be run with fuzzy logic. The flow diagram of the proposed system is shown in Figure 2.

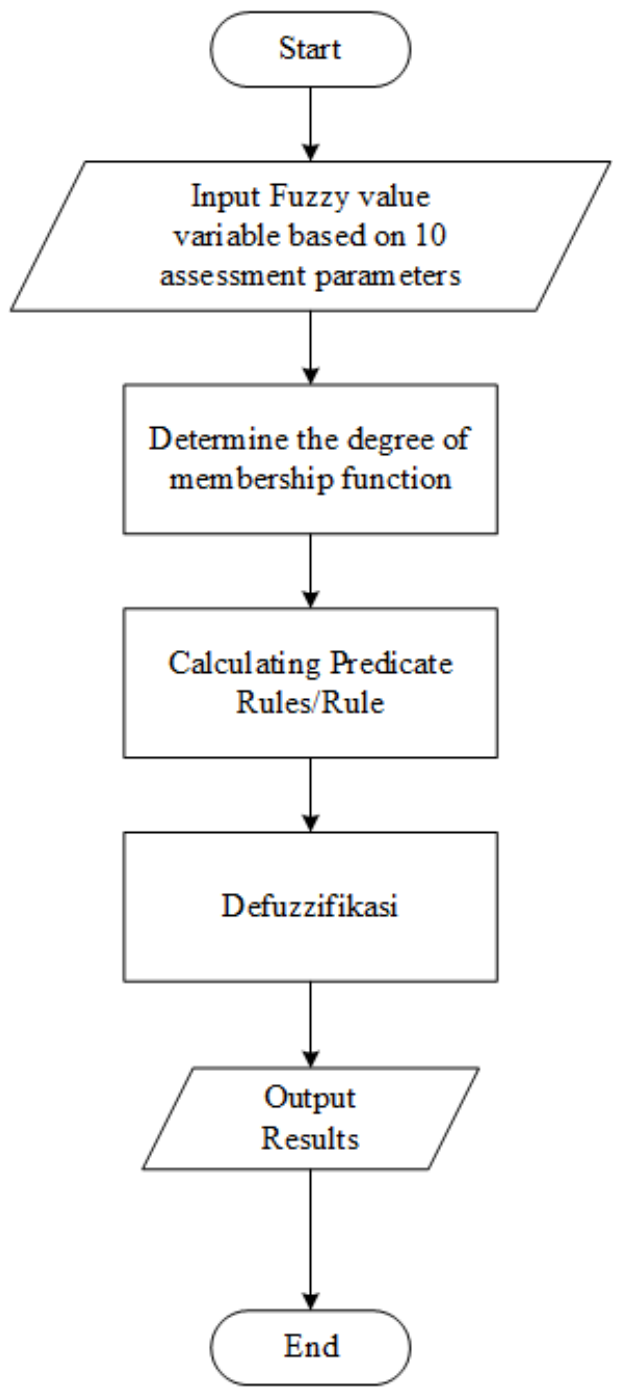

Fig. 2. Tsukamoto Method Fuzzy Flowchart.

The system workflow process shown in Figure 2 begins by entering the value of the fuzzy variables used, which consists of the variables of attitudes, knowledge, skills, and student attendance. Each variable is determined by the degree of membership $(\mu)$, where the degree becomes the value in the fuzzy set. The variables included in the fuzzy set are then formed rules that are obtained by combining each variable with its respective linguistic attributes. To determine the output results, the average defuzzification of each variable predicate is used with the following formulation:

$$
Z=\frac{\alpha 1 * Z 1+\propto 2 * Z 2+\propto 3 * Z 3+\propto 4 * Z 4}{\propto 1+\propto 2+\propto 3+\propto 4}
$$




\section{Implementation}

In this study, the teaching and learning process evaluation system is used to design and realize an information system for indicators and evaluation of the quality of the online teaching and learning process using a fuzzy-expert system algorithm. The following are some of the Fuzzy-Expert System interfaces for indicators and evaluation of the quality of the online teaching and learning process, which can be seen in Figure 3.

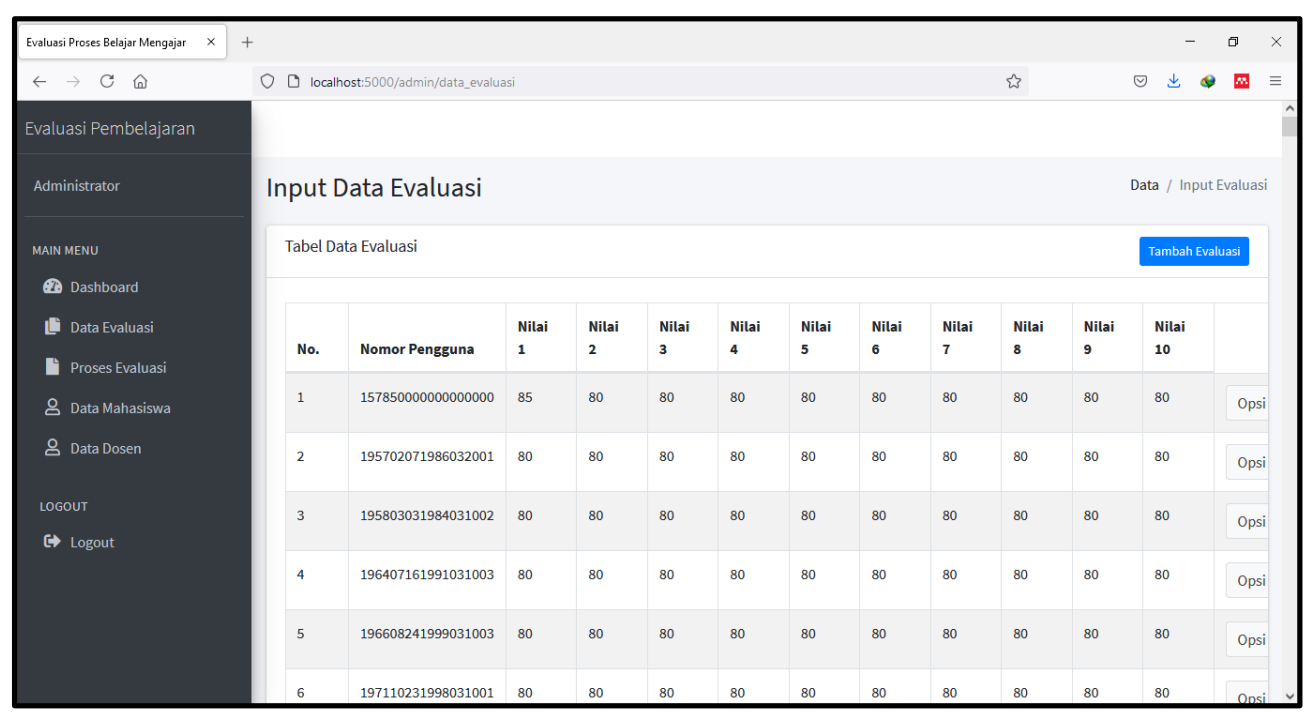

Fig. 3. Data Evaluation.

In Figure 3, This is an evaluation data page which is a fuzzy processed input data. The values 1 to 10 can be explained with explanatory information on the assessment parameters used. Click the add evaluation button to add evaluation data. The user number is the subject being assessed. Those with long user numbers are lecturers, and short users are students. Users can be seen in student or lecturer data.

Then, in the evaluation process, the expert page determines the fuzzy values in the system. Here two settings must be defined first, namely fuzzy parameters and fuzzy rules. The fuzzy parameter used is the mapping of the fuzzy values to be entered, shown in Figure 4. 


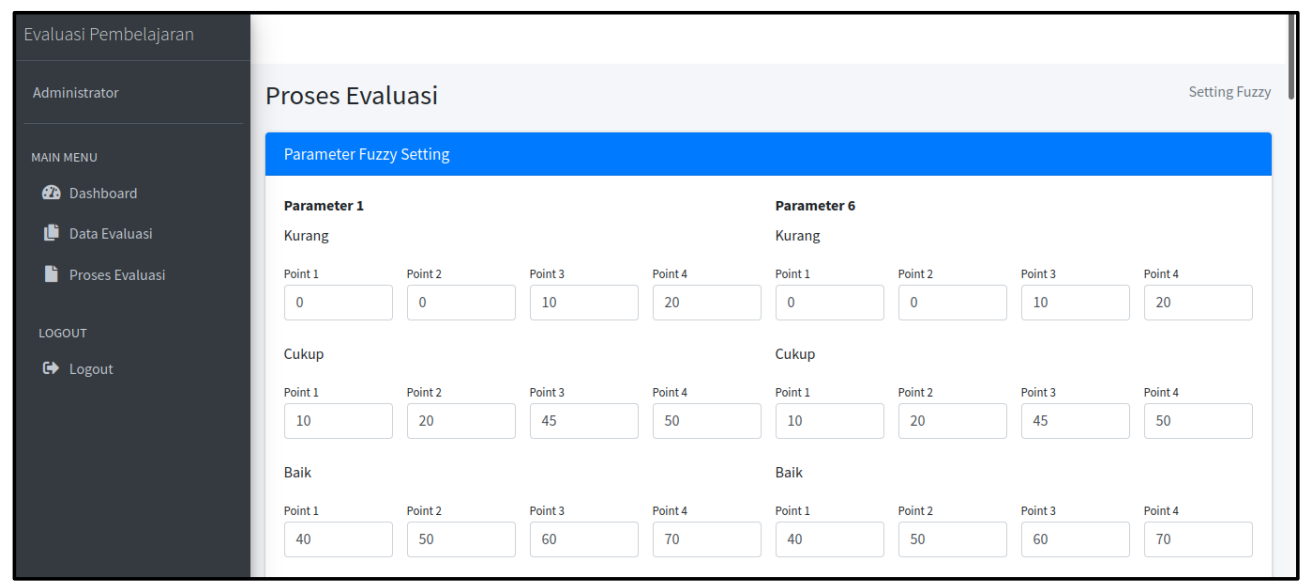

Fig. 4. Evaluation Process.

If the combined parameters are $1-10$, then the output will be the fuzzy rules. Rules can be added to assess each parameter, from the evaluation of students and lecturers in the assessment carried out by an expert. The expert here is tasked with entering the value of the assessment that has been carried out by the internal quality assurance of the ISI Surakarta Batik Fashion Design study program. These rules set from the expert system can be shown in Figure 5.

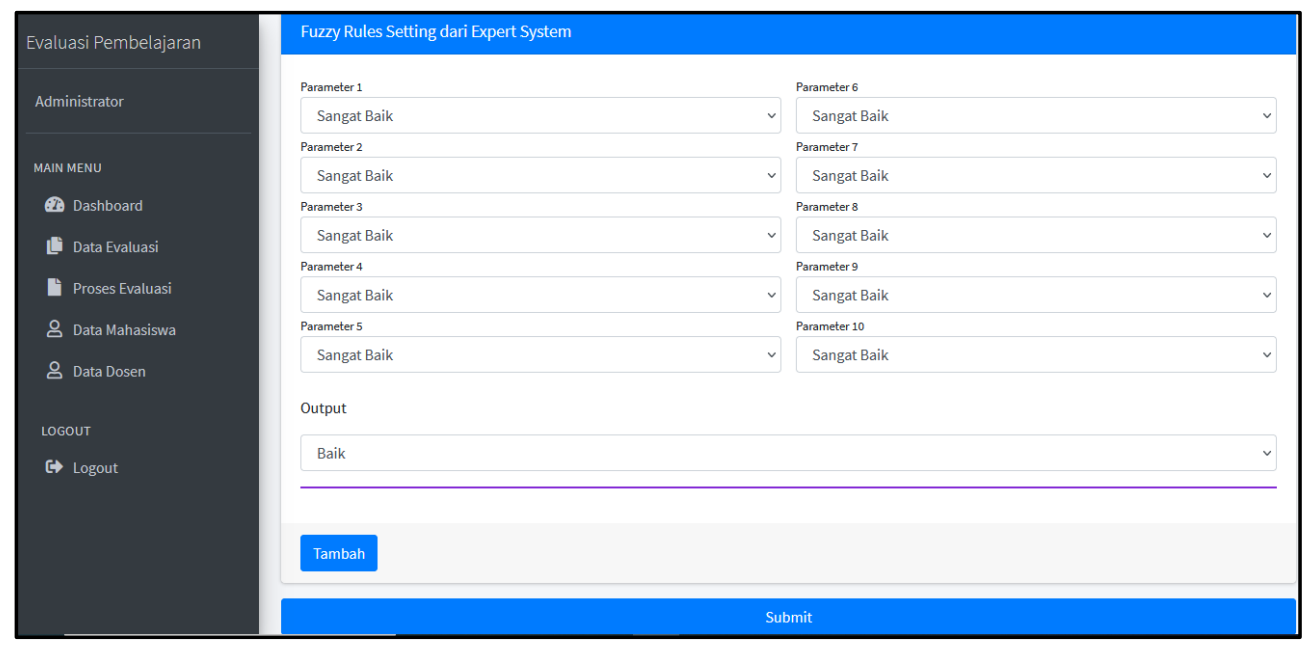

Fig. 5. Fuzzy Rules Setting from Expert System.

\section{Results and Discussion}

In the results of this study, the application of the fuzzy-expert system method is presented in tabular form according to the variables that become criteria for the assessment parameters, namely the presence of lecturers and students, the suitability of lecture material with the curriculum, activities to develop academic atmosphere, assessment of student skills, suitability of learning support facilities and infrastructure, the performance of education personnel according to the level of service satisfaction to students in the learning 
process, student attitude assessment, student knowledge assessment, lecturer exemplary assessment, and lecturer performance in teaching clarity with the use of technology as one of them is shown in Table 1.

Table 1. Parameter Assessment Results.

\begin{tabular}{|c|c|c|c|c|c|c|c|c|c|}
\hline $\mathbf{X 1}$ & $\mathbf{X 2}$ & $\mathbf{X 3}$ & $\mathbf{X 4}$ & $\mathbf{X 5}$ & $\mathbf{X 6}$ & $\mathbf{X 7}$ & $\mathbf{X 8}$ & $\mathbf{X 9}$ & $\mathbf{X 1 0}$ \\
\hline 80 & 80 & 80 & 80 & 80 & 80 & 80 & 80 & 80 & 80 \\
\hline 80 & 80 & 85 & 80 & 85 & 85 & 85 & 80 & 85 & 85 \\
\hline 85 & 85 & 85 & 85 & 85 & 85 & 80 & 80 & 80 & 80 \\
\hline 80 & 80 & 80 & 80 & 80 & 80 & 85 & 85 & 85 & 85 \\
\hline 85 & 85 & 80 & 80 & 85 & 75 & 80 & 80 & 85 & 90 \\
\hline 85 & 85 & 80 & 80 & 85 & 75 & 80 & 80 & 85 & 90 \\
\hline 85 & 85 & 80 & 80 & 85 & 75 & 80 & 80 & 85 & 90 \\
\hline 85 & 85 & 80 & 80 & 85 & 75 & 80 & 80 & 85 & 90 \\
\hline 80 & 80 & 80 & 80 & 80 & 80 & 80 & 80 & 80 & 80 \\
\hline 80 & 80 & 85 & 80 & 85 & 85 & 85 & 80 & 85 & 85 \\
\hline 85 & 85 & 85 & 85 & 85 & 85 & 80 & 80 & 80 & 80 \\
\hline 80 & 80 & 80 & 80 & 80 & 80 & 85 & 85 & 85 & 85 \\
\hline 80 & 80 & 80 & 80 & 80 & 80 & 85 & 85 & 85 & 85 \\
\hline 80 & 80 & 80 & 80 & 80 & 80 & 85 & 85 & 85 & 85 \\
\hline
\end{tabular}

Table 1. shows that each criterion that becomes the assessment parameter is an assessment input according to the number obtained with the value of each criterion. In the manual calculation process, Tsukamoto's fuzzy logic has several stages: the fuzzification stage, the rule determination stage, and the defuzzification stage. Each stage has its own rules, as the fuzzification stage has ten assessment parameters, while the determination stage is in the form of forty rules. The defuzzification stage determines the final value that regulates the output of the inference engine. The following steps are carried out in the assessment process, including:

1) Fuzzification

Table 2. Fuzzification.

\begin{tabular}{|c|c|c|c|c|}
\hline Parameter & Less & Enough & Good & Very Good \\
\hline X1 & 0,5 & 0,5 & $15 \leq 20$ & 1 \\
\hline X2 & 0,5 & 0,5 & 1 & $15 \leq 20$ \\
\hline X3 & 0,2 & 0,3 & $38 \leq 40$ & \\
\hline X4 & 0,2 & 0,3 & $23 \leq 25$ & \\
\hline X5 & 0,5 & 0,5 & $15 \leq 20$ & 1 \\
\hline X6 & 0,5 & 0,5 & 1 & $15 \leq 20$ \\
\hline X7 & 0,2 & 0,3 & $38 \leq 40$ & \\
\hline X8 & 0,2 & 0,3 & $23 \leq 25$ & \\
\hline X9 & 0,5 & 0,5 & 1 & $15 \leq 20$ \\
\hline X10 & 0,2 & 0,3 & $38 \leq 40$ & \\
\hline
\end{tabular}

Table 2. shows the fuzzification process where each parameter has been calculated its value. From this explanation, it can be seen that conditions from ten parameters are differents which evaluation results. 
2) Rules

In determining the rules used in this study there are several 40 rules. The use of this rule is enabled to calculate the alpha predicate value. However, in the discussion in this paper one of the rules will be taken as an example shown in Table 3.

Table 3. Rules.

\begin{tabular}{|c|c|c|c|}
\hline Rules & $\alpha$-predicate (n) & $\begin{array}{l}\text { Output } \\
\text { Results }\end{array}$ & $\begin{array}{c}Z \\
\text { value }\end{array}$ \\
\hline $\begin{array}{l}\text { IF Attendance of lecturers and } \\
\text { students Good And Conformity of } \\
\text { lecture material with curriculum } \\
\text { Good And Activities of } \\
\text { developing academic atmosphere } \\
\text { Good And Assessment of student } \\
\text { skills Good And Appropriateness } \\
\text { of learning support facilities and } \\
\text { infrastructure Good And } \\
\text { Performance of education staff } \\
\text { according to the level of service } \\
\text { satisfaction to students in the } \\
\text { learning process Good And } \\
\text { Assessment of student attitudes } \\
\text { Good And Student Knowledge } \\
\text { Assessment Good And Lecturer } \\
\text { Exemplary Assessment Good } \\
\text { And Lecturer Performance in } \\
\text { teaching clarity with the use of } \\
\text { technology Good THEN Good. }\end{array}$ & 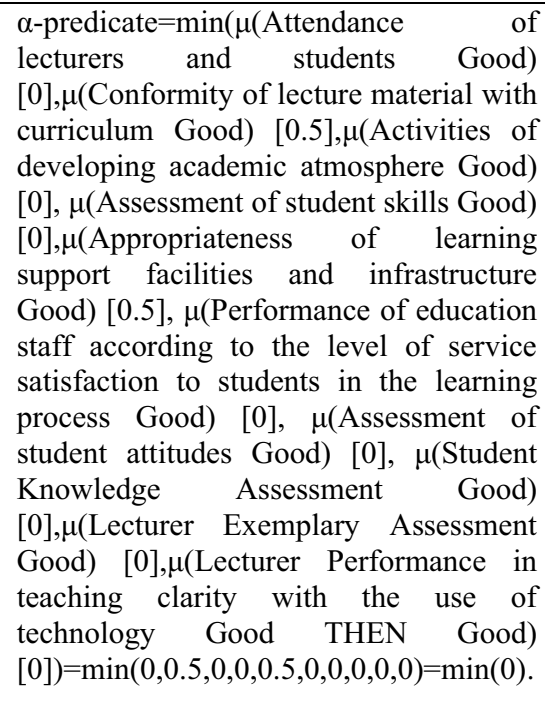 & Good & 80 \\
\hline
\end{tabular}

3) Defuzzification

In this defuzzification process, it transposes the fuzzy output to the output, from the given fuzzy set and the corresponding degree of membership.

$$
Z=\frac{0 * 80+0 * 80+0 * 80+0 * 80+\ldots+0 * 40+0 * 80+0 * 40+0 * 20}{0+0+0+1+0.3+\ldots+0.5+0+0.2+0+0}=\frac{220}{2.5}=88
$$

The final results obtained in this study are divided into two, namely assessment and evaluation. The assessment is in the form of numbers obtained while the evaluation shows the results of good, sufficient, and poor quality. For reporting the results of the assessment and evaluation outputs are shown in Table 4.

Table 4. Assessment and Evaluation Output Results Report.

\begin{tabular}{|c|c|c|c|c|c|c|c|c|c|c|c|c|c|}
\hline No & ID User & $\begin{array}{c}\text { Valu } \\
\text { e } 1 \\
\end{array}$ & $\begin{array}{c}\text { Valu } \\
\text { e } 2 \\
\end{array}$ & \begin{tabular}{|l} 
Valu \\
e 3 \\
\end{tabular} & $\begin{array}{l}\text { Valu } \\
\text { e } 4 \\
\end{array}$ & $\begin{array}{l}\text { Valu } \\
\text { e } 5 \\
\end{array}$ & $\begin{array}{l}\text { Valu } \\
\text { e } 6\end{array}$ & $\begin{array}{l}\text { Valu } \\
\text { e } 7 \\
\end{array}$ & $\begin{array}{l}\text { Valu } \\
\text { e } 8 \\
\end{array}$ & $\begin{array}{l}\text { Valu } \\
\text { e } 9 \\
\end{array}$ & $\begin{array}{l}\text { Valu } \\
\text { e } 10\end{array}$ & \multicolumn{2}{|c|}{ Results } \\
\hline 1 & $\begin{array}{l}157850000 \\
000000000 \\
\end{array}$ & 85 & 80 & 80 & 80 & 80 & 80 & 80 & 80 & 80 & 80 & 89 & Good \\
\hline 2 & $\begin{array}{l}195702071 \\
986032001 \\
\end{array}$ & 80 & 80 & 80 & 80 & 80 & 80 & 80 & 80 & 80 & 80 & 89 & Good \\
\hline 3 & $\begin{array}{l}195803031 \\
984031002 \\
\end{array}$ & 80 & 80 & 80 & 80 & 80 & 80 & 80 & 80 & 80 & 80 & 89 & Good \\
\hline 4 & $\begin{array}{l}196407161 \\
991031003 \\
\end{array}$ & 80 & 80 & 80 & 80 & 80 & 80 & 80 & 80 & 80 & 80 & 89 & Good \\
\hline 5 & $\begin{array}{l}196608241 \\
999031003 \\
\end{array}$ & 80 & 80 & 80 & 80 & 80 & 80 & 80 & 80 & 80 & 80 & 89 & Good \\
\hline 6 & $\begin{array}{l}197110231 \\
998031001 \\
\end{array}$ & 80 & 80 & 80 & 80 & 80 & 80 & 80 & 80 & 80 & 80 & 89 & Good \\
\hline
\end{tabular}




\begin{tabular}{|c|c|c|c|c|c|c|c|c|c|c|c|c|c|}
\hline 7 & $\begin{array}{l}197705052 \\
005011002\end{array}$ & 80 & 80 & 80 & 80 & 80 & 80 & 80 & 80 & 80 & 80 & 89 & Good \\
\hline 8 & $\begin{array}{l}198308032 \\
008121001\end{array}$ & 80 & 80 & 80 & 80 & 80 & 80 & 80 & 80 & 80 & 80 & 89 & Good \\
\hline 9 & $\begin{array}{l}199507232 \\
020121004\end{array}$ & 80 & 80 & 80 & 80 & 80 & 80 & 80 & 80 & 80 & 80 & 61 & $\begin{array}{c}\text { Enou } \\
\text { gh }\end{array}$ \\
\hline 10 & 12154101 & 80 & 80 & 80 & 80 & 80 & 80 & 80 & 80 & 80 & 80 & $\begin{array}{c}61 \\
\text { Enou } \\
\text { gh }\end{array}$ \\
\hline 11 & 12154102 & 80 & 80 & 80 & 80 & 80 & 80 & 80 & 80 & 80 & 80 & 11 & Less \\
\hline
\end{tabular}

\section{Conclusion}

The research results show that using the fuzzy-expert system algorithm can design and realize an information system for indicators and evaluation of the quality of the online teaching and learning process. The system that has been built has been realized using the fuzzy-expert system algorithm. The system built can perform fuzzy assessments with several assessment parameters using expert system knowledge. The system is built based on the assessment that the system provides reports on the assessment results and evaluation in the range of 80-100 good, 54-79 enough, and 0-55 less.

\section{References}

1. Y. Zhang, F. Qin, dan J. Liu, "Improving education equality and quality: Evidence from a natural experiment in China," Int. J. Educ. Dev., vol. 70, Okt (2019)

2. A. Voutilainen, T. Saaranen, dan M. Sormunen, "Conventional vs. e-learning in nursing education: A systematic review and meta-analysis," Nurse Educ. Today, vol. 50, hal. 97-103, (2017)

3. S. Caskurlu, Y. Maeda, J. C. Richardson, dan J. Lv, "A meta-analysis addressing the relationship between teaching presence and students' satisfaction and learning," Comput. Educ., vol. 157, no. May, hal. 103966, (2020)

4. O. Belash, M. Popov, N. Ryzhov, Y. Ryaskov, S. Shaposhnikov, dan M. Shestopalov, "Research on University Education Quality Assurance: Methodology and Results of Stakeholders' Satisfaction Monitoring," Procedia - Soc. Behav. Sci., vol. 214, no. June, hal. 344-358, (2015)

5. ISO, "INTERNATIONAL STANDARD Educational organizations Management systems for educational organizations - Requirements with guidance for use," vol. 2018, (2018)

6. Y. Wang, "Microprocessors and Microsystems Educational management system of colleges and universities based on embedded system and artificial intelligence," Micro process. Microsyst., vol. 82, no. January, hal. 103884, (2021)

7. H. Ajpru, S. Wongwanich, dan P. Khaikleng, "Design of Educational Quality Assurance System for Driving Policy of Educational Reform in Thailand: Theorybased Evaluation," Procedia - Soc. Behav. Sci., vol. 116, no. 22, hal. 1416-1422, (2014)

8. S. Thaker dan V. Nagori, "Analysis of Fuzzification Process in Fuzzy Expert System," Procedia Comput. Sci., vol. 132, hal. 1308-1316, (2018)

9. A. Nugroho dan A. Nugroho, "ScienceDirect Procedia ScienceDirect ScienceDirect Mobile Expert System Using Fuzzy Tsukamoto for Diagnosing Cattle Disease Mobile Expert System Using Fuzzy Tsukamoto for Diagnosing Cattle Disease," 
Procedia Comput. Sci., vol. 116, no. Iccsci, hal. 27-36, (2017)

10. G.-J. Hwang, H.-Y. Sung, S.-C. Chang, dan X.-C. Huang, “A fuzzy expert systembased adaptive learning approach to improving students' learning performances by considering affective and cognitive factors," Comput. Educ. Artif. Intell., vol. 1, no. August, hal. 100003, (2020)

11. S. Suryono, A. Khuriati, dan T. Mantoro, "A fuzzy rule-based fog-cloud computing for solar panel disturbance investigation," Cogent Eng., vol. 6, no. 1, hal. 1-19, (2019)

12. S. Sava, C. Borca, dan L. Danciu, "Models of Quality Assurance in Evaluation and Validation of Competencies, for an Easier Access to Higher Education," Procedia Soc. Behav. Sci., vol. 142, hal. 176-182, (2014)

13. Dkk Mel Barracliffe, Lisa Gardner, "Systems Development Life Cycle (SDLC) Methodology," hal. 1-9, (2009) 